\title{
LA PUBLICIDAD \\ DESDE EL PUNTO DE VISTA \\ DE LA ESCUELA AUSTRIACA
}

\author{
JORGE GARCÍA MARTÍNEZ
}

Fecha de recepción: 17 de junio de 2015

Fecha de aceptación: 29 de marzo de 2016

Resumen: En este trabajo voy a tratar la publicidad desde el punto de vista de la Escuela Austriaca de Economía. Para ello, analizaré los comentarios de Mises en la Acción Humana sobre la propaganda comercial, así como importantes teorías de la escuela, como la de la Función Empresarial, la Eficiencia dinámica o la Teoría Evolutiva de las Instituciones Sociales. El objetivo es comprobar qué relación puede haber entre dichas teorías y las distintas definiciones dadas sobre términos publicitarios por algunos de los más importantes publicistas del momento. A su vez se pretende comprobar si con la teoría austriaca puede explicarse la publicidad de forma coherente. La Escuela Austriaca de Economía aporta una visión humana y real a la ciencia económica, en la cual el individuo y sus actos son tenidos en cuenta, partiendo todo el análisis económico desde el individualismo metodológico, puesto que son los individuos los que con sus actos dan forma a la sociedad. Gracias a la visión multidisciplinar de la escuela puede entenderse perfectamente el desarrollo de la publicidad. El aumento espectacular dado en el mercado ha hecho que el número de empresas oferentes de productos y servicios crezca constantemente, a este crecimiento se une un proceso de competencia constante que ha provocado que la publicidad vaya evolucionando continuamente. Esta explicación de la publicidad, acorde con la Escuela Austriaca, coincide plenamente con la visión de algunos de los más destacados publicistas. A su vez, en este artículo se realiza una crítica directa a la propaganda políica, cuyos resultados no pueden experimentarse libremente por la sociedad y cuyas consecuencias son nefastas para la convivencia social, el desarrollo pacífico de la cooperación y coordinación de dicha sociedad y todo el necesario progreso humano. A raíz de lo estudiado, se concluye que la publicidad puede estudiarse perfectamente desde el punto de vista de la Escuela Austriaca de Economía, lo cual permite no solo comprender las ventajas económicas de la publicidad sino también los peligros de la propaganda política. 
Palabras clave: Publicidad, Propaganda políitica, Creatividad, Competencia

Title: Advertising: An Austrian viewpoint.

Abstract: In this paper I will try advertising from the point of view of the School of Austrian Economics. To do this, I will analyze the Mises's comments in Human Action about commercial propaganda, and also school important theories, such as the Business Function, Dynamic Efficiency or Evolutionary Theory of Social Institutions. The aim is to check what relationship may be between these theories and the different definitions given about Advertising terms by some of the most important publishers of the moment. At the same time, it is intended to check whether advertising can be consistently explained with the Austrian theory. The Austrian School of Economics brings a human and real vision to the economical science, in which the individual and his actions are taken into account, starting all economic analysis from methodological individvalism, as are the individuals who by their actions give shape to the society. Thanks to the multidisciplinary approach of the school one can perfectly understand the development of advertising. The spectacular increase in the market has caused that the number of companies offering products and services constantly grows, this growth binds a process of constant competition which has led the advertising to a continually evolve. This explanation of advertising, according to the Austrian School, fully agrees with the view of some of the leading advertisers. In turn, this article is a direct criticism of the political propagan$\mathrm{da}$, in which the results cannot be experienced freely by society and whose consequences are disastrous for social coexistence, the peaceful development of the cooperation and coordination of the company and all necessary human progress. Following the study, it concludes that advertising can be perfectly studied from the point of view of the Austrian School of Economics, which allows not only understand the economic benefits of advertising but also the dangers of political propaganda.

Key Words: Advertising, Political Propaganda, Creativity, Competence 


\section{LA ESCUELA AUSTRIACA DE ECONOMÍA Y SU VISIÓN MULTIDISCIPLINAR}

La Escuela Austriaca de Economía fue fundada en 1871 por Carl Menger (1840-1921) con la publicación de su libro, Principios de Economía Política (Grundsätze der Volkswirthschaftslehre) ${ }^{1}$. Menger, ante los diversos planteamientos enfrentados existentes en el mundo de la economía, historia y ciencias sociales decidió comenzar su investigación económica partiendo de cero. El origen de toda ciencia social: La acción humana. Partiendo de este hecho y con un concepto subjetivista comenzó a elaborar un brillante análisis que sería desarrollado y completado por su discípulo Ludwig Von Mises (1881-1973) y el discípulo de éste, Friedrich August Von Hayek (1899-1992).

Conviene mencionar el detallado estudio que ha realizado el doctor César Martínez Meseguer sobre la Escuela Austriaca de Economía en lo referente a la historia y epistemología de la escuela, análisis de los distintos aportes filosóficos e históricos a la corriente subjetivista y análisis sobre las instituciones evolutivas². Meseguer (2006), pp. 143

${ }^{1}$ Carl Menger, Principios de Economía política, Unión Editorial, Madrid 1983.

${ }^{2}$ César Martínez Meseguer, La teoría evolutiva de las instituciones, la perspectiva austriaca, Unión Editorial, Madrid 2006. Dicho autor, realiza una introducción a la epistemología de la escuela en su segunda edición, op, cit., p. 143 al indicar que:

«...hemos descrito, a rasgos generales, las principales corrientes de pensamiento con las que se encontró Carl Menger al comenzar a desarrollar sus trabajos: los distintos conceptos contrapuestos del mundo (el dinámico y el estático), las diferentes ideas sobre las normas que deben regular el actuar humano (leyes generales, abstractas y de origen evolutivo, frente a mandatos y reglamentos), las interpretaciones metodológicas (las que buscan un método para las Siencias Sociales diferente al de las Ciencias Naturales y las que pretenden, a toda costa, copiar e implantar la metodología de las Ciencias Naturales en el ámbito de las Ciencias Sociales), etc.»

Ante tales contradicciones, Menger recurrió a la mejor solución posible para elaborar sus teorías y buscar el método adecuado, es decir, retrotraer su punto de partida al origen, a lo más fundamental y básico de toda Ciencia Social: el ser humano que actúa — La Acción. De esta manera, partiendo de la idea de la acción humana y del subjetivismo, consiguió elaborar toda una teoría referente 
La Escuela Austriaca considera que cada persona tiene unas valoraciones subjetivas propias y una innata capacidad creativa. El hombre, tiene unos fines que varían dependiendo de las valoraciones subjetivas de cada persona, cada uno atribuye un determinado valor subjetivo y busca medios para lograr dicho fin $\mathrm{u}$ objetivo, medios a los que atribuye una utilidad subjetiva.

Por ello, en el momento en el que se produce una necesidad en el hombre (fruto de la escasez), y éste tiene la facultad racional para ir descubriendo los medios necesarios para lograr satisfacer dicha necesidad, tenderá a actuar para conseguir lograr dicho fin.

Cuando la acción no implica ningún intercambio con otras personas se denomina Autística, sin embargo Menger analizó las relaciones de intercambio dadas en la sociedad. Si se produce una diferencia en las valoraciones subjetivas de dos personas de tal forma que el sujeto "A» valora más subjetivamente lo que tiene el sujeto «B» que lo que él mismo tiene y viceversa, y se respetan además los derechos de propiedad de tal forma que «A» no iniciará una acción violenta para robar a «B» ni viceversa, tenderá a producirse un intercambio.

Comportamientos como este suponen grandes ventajas para las partes implicadas (win-win), el hecho de que sea útil y pragmático imitarlos da lugar al surgimiento de las instituciones, las cuales son de tipo espontáneo y evolutivo.

Posteriormente, Ludwig Von Mises amplió el concepto de estudio iniciado por Menger en su obra, La Acción Humana, publicada en $1949^{3}$.

En la misma, Mises analiza amplia y detalladamente la acción humana, abordándola tanto desde el punto de vista individualista (intercambio aislado o autístico) como desde el punto de vista de las relaciones de intercambio.

Mises denomina como Praxeología (palabra derivada de la raíz griega praxis: acción) a la Teoría General de la Acción, cuyo núcleo principal es la teoría del mercado, a la cual denomina Cataláctica (derivado de la palabra griega Katallattein: permutar).

a las relaciones de intercambio y a su producto más fundamental que son las Instituciones Sociales Evolutivas (el Derecho, el mercado, el dinero..)».

${ }^{3}$ Ludwig Von Mises, La Acción Humana, Unión Editorial, Madrid 1980. 
Para Mises, la acción humana es un axioma irreducible a priori, a partir del cual pueden irse construyendo teorías económicas usando el método apriorístico deductivo, con el cual analizar las relaciones de intercambio dadas en la sociedad.

Posteriormente Hayek amplió el estudio de Carl Menger sobre las instituciones sociales evolutivas, que surgen de manera espontánea.

Por orden espontáneo se entiende el resultado no intencionado de una serie de hábitos y costumbres que surgen del hecho de que los intentos de adaptación de los individuos a las condiciones sociales de cada momento en la búsqueda de sus propios beneficios son imitados. Son imitados por la mayoría de individuos, si estos comportamientos facilitan la consecución del mayor número posible de objetivos individuales. Esta imitación conlleva a su vez un proceso de ensayo-error en el cual preponderan los grupos de individuos que eligen el comportamiento más útil para resolver sus problemas y lograr sus objetivos. De tal forma que dichos comportamientos se convierten, al ser imitados, en hábitos y costumbres que van modificándose con el tiempo (tendiendo a perdurar las mejores), que aprovechan una gran cantidad de información y conocimiento tácito acumulado durante siglos, que permiten el desarrollo (debido a que el hombre busca lo mejor para sí mismo sabiendo que no es autárquico y tiene que cooperar y coordinarse con los demás).

El grado de complejidad que puede alcanzar un orden espontáneo es prácticamente infinito y con una red de interrelaciones tan intrincada que puede rebasar los límites de la mente. La sociedad humana o lo que Hayek denominaba orden extenso ${ }^{4}$, es un orden espontáneo sin plan, en el cual los individuos gozan de absoluta libertad con el único requisito de respetar las leyes generales que buscan la compatibilidad de dichos intereses propios. Estas leyes son reglas de tipo general (se aplican a todo individuo sin distinción de la esfera en que se encuentre), abstractas, puesto que establecen condiciones que deben ser acatadas pero respetando las diferentes acciones que no vulneran su contenido, y evolutivas.

\footnotetext{
${ }^{4}$ Hayek se dedicó a ampliar el estudio iniciado por Menger en su obra. Mientras que Mises se dedicó a estudiar la Acción Humana y las relaciones de intercambio, Hayek realizó un profundo análisis sobre las instituciones sociales evolutivas.
} 
La sociedad, si bien es un orden espontáneo inmenso sin plan, está compuesta a su vez por múltiples instituciones sociales evolutivas que siguen el mismo patrón explicado anteriormente. Dichas instituciones son el Mercado, el Derecho, el Dinero, el Lenguaje, la Moral o la Familia entre otras.

La institución del mercado puede entenderse además de dos formas:

1. Como un símil de la sociedad, esta es una visión muy amplia ligada al concepto de Catalaxia. El ser humano no puede ser autárquico, viéndose obligado a cooperar y coordinarse con los demás, esto implica realizar constantes intercambios sociales, por lo que, tal y como indica el Doctor Jesús Huerta de Soto en su obra Socialismo, Calculó económico y función empresarial ${ }^{5}$, el mercado y la sociedad son sinónimos:

En suma, podríamos concluir definiendo la sociedad como un proceso (es decir, una estructura dinámica) de tipo espontáneo, es decir, no diseñado conscientemente por nadie; muy complejo, pues está constituido por miles de millones de personas con una casi infinita variedad de objetivos, gustos, valoraciones y conocimientos prácticos; de interacciones humanas (que básicamente son relaciones de intercambio que en muchas ocasiones se plasman en precios monetarios y siempre se efectúan según unas normas, hábitos o pautas de conducta); movidas todas ellas por la fuerza de la función empresarial; que constantemente crea, descubre, transmite información sobre fines y medios, ajustando y coordinando de forma competitiva los planes contradictorios de los individuos; $y$ haciendo posible la vida en común de todos ellos con un número y una complejidad y riqueza de matices y elementos cada vez mayores $^{6}$ (Huerta de Soto 1992), pp. 84-85.

2. Como institución de intercambio en sentido estricto, es decir, intercambio basado en los precios monetarios.

\footnotetext{
${ }^{5}$ Jesús Huerta de Soto, Socialismo, Cálculo Económico y Función Empresarial, Unión Editorial, Madrid 1992.

${ }^{6}$ Op. cit., pp. 84-85.
} 
Por ello, puede decirse que la Escuela Austriaca de Economía tiene una visión multidisciplinar, la cual concibe al ser humano como un ser único e irrepetible, dotado de valoraciones subjetivas propias y una innata capacidad creativa, ser humano que actúa buscando sus propios beneficios y que se encuentra en una incertidumbre inerradicable constante, por lo que utiliza las instituciones sociales y la creatividad (función empresarial) como medio para poder alcanzar sus fines.

Además, la escuela no solo parte del análisis apriorístico deductivo sino que también utiliza el método de análisis subjetivista, mediante el cual defiende que la capacidad racional del hombre es limitada, pues nuestro cerebro es resultado de una evolución y sigue evolucionando permanentemente. El ser humano no puede llegar a conocimientos eternos, universales e inmutables. El científico social debe perseguir hallar la verdad en su estudio de la sociedad, sabiendo que jamás podrá obtener certezas absolutas. Además, debe añadirse que, dada la incertidumbre inerradicable y dada la imposibilidad de medir ciertas variables de manera rigurosa, no pueden alcanzarse certezas absolutas en economía. Solo pueden hacerse predicciones o leyes económicas de tendencia mediante la teoría, predicciones que parten del axioma de la acción humana y que se han desarrollado mediante el método apriorístico-deductivo.

La Escuela Austriaca, defiende además las ideas de libertad

Muchos de los primeros liberales defendían la libertad del individuo desde un punto de vista iusnaturalista, creyendo que los derechos y las libertades eran sagrados ya fuese desde el punto de vista de la razón o la fe.

Sin embargo no hace falta entrar en temas de religión o darle un exceso de importancia a la razón para defender la libertad llegando a verdades absolutas. La Escuela Austriaca defiende que la capacidad racional del hombre es limitada, el cerebro es resultado de una evolución.

Mientras que el proceso evolutivo en el cual se forman las instituciones comprende cientos o en algunos caso miles de años, el concepto de tiempo que tiene el ser humano es finito, nuestra vida no es eterna, da igual que tengamos un símbolo matemático para definir el infinito. En última instancia no podemos comprender el concepto de eternidad, pues supera nuestra capacidad racional. 
Por ello, el científico social no puede desde nuestro punto de vista afirmar que se pueden llegar a obtener conocimientos universales, eternos e inmutables. No puede llegarse a la certeza, en todo caso, el científico social deberá buscar siempre aproximarse lo máximo posible a la verdad ${ }^{7}$.

Si bien es cierto que importantes autores como John Locke (16321704) defendieron la libertad desde un punto de vista iusnaturalista, logrando importantes resultados con sus acciones, no es necesario recurrir a un exceso de razón para ello.

Desde el punto de vista evolutivo-institucional, podemos observar cómo el ser humano, al no poder ser autárquico, coopera y se coordina con los demás, formándose así la sociedad. Pero esta cooperación y coordinación es precisamente posible gracias a que cada ser humano busca, con sus acciones, lo mejor para sí mismo. El ser humano actúa porque quiere lograr un objetivo que le es beneficioso para consigo mismo, de ahí que el surgimiento de las instituciones se deba a la imitación espontánea de comportamientos que son útiles para una amplia mayoría de personas.

En otras palabras, cada ser humano, movido por la Función Empresarial, actúa libremente en sociedad realizando asociaciones voluntarias o intercambios con otras personas, que le permiten cooperar y coordinarse, generándose así nueva información práctica constantemente.

Tal y como dijo Ludwig Von Mises en su obra «Liberalismo, la tradición clásica» de 1927:

Cuando en el siglo XVIII y en la primera mitad del xIX empezó el liberalismo a abolir la servidumbre de la gleba y la sujeción de las

${ }^{7}$ Respecto al conocimiento de verdades y certezas, César Martínez Meseguer, en su obra La Teoría Evolutiva de las instituciones, la perspectiva austriaca, Unión Editorial, Madrid 2006, p.185 afirma:

...el científico debe renunciar a perseguir el conocimiento de certezas (conocimiento seguro o verdades absolutas sin posibilidad de error) y debe limitarse a buscar simples aproximaciones a la verdad, entendida como la conformidad de las cosas con el concepto o modelo que se elabora de ellas en la mente. Por ello el científico debería buscar exclusivamente "verdades" (que, según esta concepción, pueden entenderse como imparciales, incompletas etc), y no "la certeza" (que por definición no puede ser limitada o "incierta"). 
poblaciones campesinas en Europa, y la esclavitud de los negros en las colonias de Ultramar, no pocos filántropos sinceros manifestaron su contrariedad (...) Cuando a quienes recomendaban la abolición de la esclavitud sólo por motivos genéricamente humanitarios se les objetaba que el mantenimiento del sistema seria también de interés de los propios esclavos, no tenían ningún argumento serio con que replicar. Pues para replicar esta objeción a favor de la esclavitud solo existe un argumento que refuta y siempre a refutado a todos los demás: que el trabajo libre es incomparablemente más productivo que el efectuado por quien no es libre ${ }^{8}$ (Mises 2008), pp. 50-51.

Es decir. La libertad es necesaria porque cada persona, en la búsqueda de sus propios beneficios tenderá a ofrecer algo a cambio al resto. Si el trabajo libre es incomparablemente más productivo que el trabajo esclavo es porque el hombre, al buscar su propio beneficio en el mercado, se ve obligado a ofrecer lo mejor de sí mismo a los demás.

El mercado es voluntario, nadie puede obligar a comprar sus productos a los demás, por lo que cuanto mejor sean esos productos y servicios, más beneficio obtendrá esa persona. Esta es la magia de la Función empresarial, la gente, buscando sus propios beneficios en un orden espontáneo de cooperación y coordinación, se ve en la tesitura de que cuanto mejor sea lo que ofrezca, más probable es que sus objetivos se vean cumplidos. Produciéndose así una constante competencia entre todo el mundo, que mueve la sociedad hacia un progreso constante.

Cada persona es única e irrepetible, dotada de unas valoraciones subjetivas propias y una innata capacidad creativa, esto nos lleva a pensar que la libertad es necesaria porque el soberano es el individuo, no la sociedad, ni la familia, ni los más próximos allegados.

En definitiva, lo pragmático es defender que mientras que un individuo no dañe los principios jurídicos básicos del derecho evolutivo de otras personas (defensa de la vida, la propiedad, la

${ }^{8}$ Ludwig Von Mises, Liberalismo, la tradición clásica, Unión Editorial, Madrid 2007, p. 50-51. 
libertad, cumplimiento de los contratos y búsqueda de la felicidad) este pueda actuar con total libertad.

El dirigir la vida de los demás desde arriba dañando esta libertad sólo será causa de conflicto social y violencia.

II

LA PUBLICIDAD Y EL MERCADO LIBRE

\section{La propaganda comercial desde la perspectiva de Mises}

Una vez aclarados ciertos aspectos epistemológicos básicos de la Escuela Austriaca es momento para pasar a analizar en detalle la publicidad y las relaciones públicas desde la perspectiva de la escuela, que es el objetivo de este trabajo.

Para ello consideramos oportuno empezar por las similitudes entre la definición de publicidad o propaganda comercial de Ludwig Von Mises con las definiciones de otros importantes publicistas.

En su obra La Acción Humana, Mises dedica un tema a la propaganda comercial. Al fin y al cabo, como ahora veremos, la publicidad o propaganda comercial es una parte vital del mercado, en concreto es la punta de lanza del mismo.

Mises trata varios temas en su capítulo sobre la publicidad que dan para varios puntos de este trabajo, no solo se dedica a definir la publicidad, sino que también toca el tema de si ésta debe ser prohibida o controlada por el estado, hasta qué punto condiciona la actitud de la gente, la propaganda política o el proceso ensayo error constante del mercado.

Sin embargo, tal y como he indicado al principio, creo considerable tratar en este punto las características básicas de la publicidad según Mises y compararlas con las de algunos publicistas de renombre y con experiencia en el sector.

Mises comienza indicando que el consumidor no es omnisciente:

El consumidor no es omnisciente. A menudo no sabe dónde encontrar lo que busca al precio más barato posible. Muchas veces in- 
cluso ignora qué mercancía o servicio es el más idóneo para suprimir el específico malestar que le atormenta. El consumidor únicamente conoce las circunstancias que el mercado registro en el inmediato pretérito. De ahí que la misión de la propaganda comercial consista en brindarle información acerca del actual estado de las $\operatorname{cosas}^{9}$ (Mises 1980), pp.

Recordemos que la sociedad consiste esencialmente en un orden espontáneo sin plan en el que se produce una cooperación y coordinación de los individuos constante. Esa cooperación ha sido principalmente hegemónica durante la inmensa mayoría de la historia humana. Sin embargo, desde la Revolución Industrial (1850) predominan los contratos voluntarios ${ }^{10}$. El ser humano vive en lo que Hayek denominaba la «sociedad abierta», el orden extenso u orden sin plan, en el cual, las interacciones de los individuos que buscan sus propios fines en el mercado generan un volumen de información constante inmenso ${ }^{11}$.

Por ello, es fácilmente entendible, que los consumidores no puedan ser omniscientes. Es imposible que estén al tanto de toda las cientos de miles de ofertas comerciales que surgen cada minuto.

También es extremadamente importante el argumento que expone Mises en torno al hecho de que mucha gente ignora qué es exactamente lo que desea ${ }^{12}$.

El consumidor, como dice Mises, «únicamente conoce las circunstancias que el mercado registró en el inmediato pretérito». Por

${ }_{9}$ Ludwig Von Mises, La Acción Humana, Unión Editorial, Madrid 1980. P. 386.

${ }^{10}$ Mises, en La Acción Humana, página 234 dice:

Existen dos diferentes formas de cooperación social: la cooperación en virtud del contrato y la coordinación voluntaria, y la coordinación en virtud del mando y la subordinación, es decir, hegemónica.

La sociedad basada en vínculos contractuales se basa principalmente en relaciones simétricas entre los individuos, en dichas relaciones no hay coacción de ningún tipo, ningún individuo impone a otro sus objetivos sino que cada persona busca la consecución de sus propios fines, usando el mercado como medio para ello.

${ }^{11}$ En el siguiente punto, analizaremos a fondo las relaciones entre la Función Empresarial y la publicidad, así como toda la información de tipo práctico o creativo que se genera constantemente en el mercado.

${ }^{12}$ Este aspecto será analizado con detalle en uno de los puntos siguientes en el que se tratará la relación entre la publicidad y la Teoría de la Eficiencia Dinámica. 
ello, el objetivo de la publicidad es principalmente el de informar a los consumidores.

El oferente ofrece su producto o servicio a la sociedad para lograr sus objetivos. Es decir, el producto o servicio es un medio para lograr sus fines (en este caso obtener dinero a cambio de intercambiar dicho producto o prestar el servicio). Por ello, la publicidad es un medio para lograr dicho fin. El vendedor de zapatos tiene como fin último ganar dinero, el medio para ganarlo es vender dichos zapatos, el hecho de realizar esta venta, es a su vez un fin, cuyo medio es anunciar o informar a los consumidores de que se están vendiendo dichos zapatos.

Esto supone un problema añadido. Puesto que el mercado es competitivo, no solo basta con anunciar o informar del producto o servicio, tiene que conseguir despertar la curiosidad del consumidor haciendo que este deje de lado las múltiples ofertas comerciales de la competencia. Por ello tal y como dice Mises:

La propaganda comercial debe ser chillona y llamativa (...) para tener éxito debe acomodarse a la mentalidad común. Ha de seguir los gustos y hablar el lenguaje de la muchedumbre. Por eso es vocinglera, escandalosa, burda, exagerada, porque la gente no reacciona ante la delicada insinuación. Es el mal gusto del público lo que obliga al anunciante a desplegar idéntico mal gusto en las campañas. (...) La publicidad, al igual que cuanto pretende acomodarse al mal gusto de las masas, repugna a las almas que se estiman refinadas. Por eso muchos menosprecian la propaganda comercial $^{13}$ (Mises 1980), pp. 386.

Estas observaciones de Mises dan pie a varias explicaciones detalladas al respecto:

1. Los gustos no son ni mucho menos comunes, hay cientos de miles de públicos objetivos distintos. Cada persona tiene unas valoraciones subjetivas propias, un mismo hecho puede ser vivido por dos personas de manera totalmente diferente.

${ }^{13}$ Ludwig Von Mises, La Acción Humana, Unión Editorial, Madrid 1980. P. 386. 
Tal y como indican Philip Kotler y Gary Armstrong en su libro Fundamentos del Marketing:

Un público es cualquier grupo que tiene un interés real o potencial en, o impactando sobre, la capacidad de una organización para alcanzar sus objetivos ${ }^{14}$ (Kotler y Amstrong 2008), pp. 67.

Asumiendo que el objetivo de la empresa es vender su producto o servicio, lo cual es un medio para poder ganar dinero, podemos decir que los clientes de la empresa son un medio para vender ese producto o servicio o incluso un fin en sí mismo.

Sobre el tema del lenguaje, la sociedad como orden espontáneo de cooperación y coordinación que es, genera una cantidad de información creativa nueva constante muy grande. Ello sumado al contante proceso de ensayo y error que se da en todas las instituciones hace que la cultura esté constantemente evolucionando. No solo instituciones como el mercado o el lenguaje están evolucionando constantemente, también otras como la familia.

A mediados de los años 50 del siglo xx el publicista debía dirigirse a un entorno familiar en el que el hombre trabajaba duramente y la mujer se dedicaba a cuidar a los niños en casa, eso se acabó. Hoy en día el concepto de «hogar tradicional» está quedando relegado por una nueva explosión multicultural en la cual una familia puede ser prácticamente de cualquier tipo: mujer y hombre, hombre y hombre, mujer y mujer...ello sin contar con que el papel de la mujer en el trabajo ha cambiado por completo e incluso el papel del hombre lo ha hecho. Ahora por ejemplo un hombre puede coger bajas maternales.

Esto ha dado a la publicidad una amplísima gama de públicos a los que dirigirse. Es decir, el concepto de familia, o el público objetivo familiar ha sufrido una segmentación inmensa, segmentación que probablemente siga acrecentándose con el tiempo, y a la que los publicistas tendrán sin duda que adaptarse.

Pero quizás lo más interesante sobre que los publicistas deban adaptarse a los nuevos tiempos sean las nuevas tecnologías. Internet

${ }^{14}$ Kotler y Amstrong, Fundamentos del Marketing, Pearson Education, Naucalpan de Juárez, Estado de México 2008. P. 67. 
es sin duda alguna un antes y un después, que está marcando y marcará de forma muy intensa el modo de relacionarse de la gente y las posibilidades de progreso de la sociedad humana.

Tal y como indican Kotler y Amstrong;

Una buena parte de las operaciones de negocios actuales se efectúa a través de redes que conectan a personas y compañías ${ }^{15}$ (Kotler y Amstrong 2008), pp. 437.

Internet está totalmente presente en nuestras vidas, y ha supuesto un avance inmenso para el progreso humano. Desde un punto de vista económico, podríamos decir sin temor a equivocarnos que el mercado libre implica la soberanía del consumidor.

En una sociedad libre de intercambios voluntarios es obvio que el oferente debe ofrecer lo mejor al demandante, siendo este demandante el que ponga las normas. Internet ha influido positivamente en ese proceso haciendo que los beneficios de los compradores sean mucho mayores que hace años ${ }^{16}$.

Es decir, los consumidores tenemos todo a golpe de click con unas facilidades inmensas con respecto a hace menos de 30 años. Pero la tecnología no solo ha supuesto una ventaja para el consumidor, también para el oferente. Hoy en día y gracias a Internet, el cliente puede interactuar con el oferente de forma constante, afianzando así la fidelización del mismo e indicando al oferente las ventajas y desventajas de su producto e imagen corporativa.

${ }^{15}$ Kotler y Amstrong, Fundamentos del Marketing, Pearson Education, Naucalpan de Juárez, Estado de México 2008. P. 437.

${ }_{16}$ Tal y como indican Kotler y Amstrong: «Las compras por internet benefician de muchas maneras tanto a los compradores finales como a compradores industriales. Pueden ser cómodas: los clientes no tienen que batallar con el tráfico, buscar dónde estacionarse, ni recorrer tiendas y pasillos para encontrar y examinar productos. Pueden comparar ofertas navegando por sitios web (...) comprar es fácil y privado; los clientes enfrentan menos trámites y no tienen que toparse con vendedores ni quedar expuestos a la persuasión ni a las influencias emocionales que buscan convencerlos de comprar. (...) Además, internet a menudo ofrece a los compradores mayor acceso a productos y mayor surtido. Al no estar limitados por las fronteras físicas, los vendedores web pueden ofrecer al consumidor un surtido casi ilimitado de productos en cualquier lugar del mundo. (...) Ninguna tienda tradicional podría ofrecer un acceso tan fácil a un surtido tan extenso». Op. cit., pp. 438. 
Además, gracias al comercio web, los oferentes se pueden hacer con una cantidad de datos inmensa que les permiten segmentar al público hasta llegar al extremo de que en muchos casos la empresa ya no se dirige a un público objetivo concreto que abarque un sector de la población (por ejemplo gente de entre 20 y 25 años buscando empleo) sino que se dirige al individuo en sí.

Este hecho se está acrecentando y, muy probablemente, gracias a las nuevas tecnologías (impresoras 3D por ejemplo) se llegue en un futuro a una situación en la cual la publicidad sea totalmente personalizada, dirigiéndose las marcas de forma directa al individuo, ahorrándose así tiempo y obteniendo una mayor probabilidad de éxito en la compra.

Con este ejemplo podemos comprobar cómo la misión de brindar información sobre el actual estado de las cosas que para Mises tiene la publicidad va especializándose, focalizando cada vez más la industria publicitaria sus objetivos en los individuos a los cuales tiene como objetivo impactar, y por ende, aumentando su eficiencia.

2. Los individuos reciben miles de impactos publicitarios al día, muchos de ellos son de productos y marcas de las que no son público objetivo, pero incluso aun dentro del rango de productos y servicios que sí son de su gusto, son cientos de marcas las que compiten por lograr que dicho individuo les compre, de ahí que la publicidad que realicen deba ser vocinglera, escandalosa, burda y exagerada. El consumidor no tiene tiempo ni motivo para pararse a ver el anuncio de forma detallada, sería imposible que pudiese hacer sus tareas diarias si estuviese entretenido en analizar toda la publicidad que le rodea. A ello debe añadirse el hecho de que la mayoría de los consumidores no recuerdan ni la mitad de los anuncios que han visto a lo largo de un día. Por ello, la publicidad debe sorprender al consumidor para una vez haber llamado su atención, informarle de la manera más rápida, concisa y detallada de las ventajas del producto o servicio que se está anunciando.

El concepto de competencia es extremadamente importante, tal y como indica el profesor Huerta de Soto: 
La función empresarial, por su propia naturaleza es siempre competitiva (competencia procede etimológicamente del latín: cumpetitio (concurrencia múltiple de peticiones sobre una cosa a la que hay que adjudicar su dueño). Quiere ello decir que una vez que se descubre por el actor una determinada oportunidad de ganancia y éste actúa para aprovecharla, dicha oportunidad de ganancia desaparece, y ya no puede ser apreciada y aprovechada por otro ${ }^{17}$. (Huerta de Soto, 1992), pp. 77.

Es decir, supongamos que tenemos dos marcas de zapatillas deportivas compitiendo por el mismo público objetivo, que puede ser gente joven de entre 20 y 40 años que tiene una vida ajetreada y dedica sus ratos libres a hacer deporte de alta resistencia como pueden ser pruebas de triatlón etc. El objetivo de cada una de esas dos marcas es que dicho individuo que forma parte de su público objetivo compre el producto.

Por ello, las dos marcas de zapatillas tendrán que competir siguiendo los gustos de dicho público objetivo o tipo de consumidor, usando su lenguaje (palabras como Triatlón, IroMan etc) y siendo lo más llamativas posibles para convencer a dicho individuo en el menor tiempo posible de que su producto (zapatillas de deporte) es el mejor de todos $^{18}$.

A su vez, las dos marcas deberán intentar fidelizar al cliente para que siga comprando sus productos.

Este proceso de competencia y fidelización se ha ido incrementando desde la mitad del siglo xx dando lugar al Marketing.

Tal y como indican Kotler y Amstrong:

\footnotetext{
${ }^{17}$ Jesús Huerta de Soto, Socialismo, Cálculo Económico y Función Empresarial, Unión Editorial, Madrid 1992. P. 77.

18 A este respecto es interesante la aportación de Kotler y Amstrong, quienes en su libro Fundamentos del Marketing, (Pearson Education, Naucalpan de Juárez, Estado de México 2008. P. 67) indican: «para tener éxito una empresa debe proporcionar a sus clientes mayor valor y satisfacción que los competidores. Por lo tanto, el mercadólogo debe hacer algo más que simplemente adaptarse a las necesidades de los consumidores meta; también debe obtener ventaja estratégica mediante el posicionamiento vigoroso de su oferta en la mente de los consumidores en comparación con las ofertas de la competencia».
} 
El Marketing, más que ninguna otra función de negocios, se ocupa de los clientes. (...) es la administración de las relaciones perdurables con los clientes. La doble meta del marketing es atraer nuevos clientes al prometer un valor superior y conservar y aumentar a los clientes actuales mediante la entrega y satisfacción ${ }^{19}$ (Kotler y Amstrong 2008), pp. 5.

Es decir, el marketing tiene como objetivo fidelizar y mantener a los clientes que la empresa ya tiene y atraer nuevos clientes. Esto está directamente relacionado con la competencia. Es el aumento constante de oferentes (es decir el surgimiento de nuevas empresas que compiten entre sí) lo que ha llevado a los mismos a tener que innovar, no solo a la hora de adaptarse al mercado, la sociedad o el lenguaje (como vimos en la primera observación) sino también a una situación en la cual deben mantener al cliente que ya tienen y atraer constantemente a nuevos.

Esto evidentemente no supone sino ventajas constantes para los consumidores como ya se ha indicado en la anterior observación.

3. Los oferentes, si bien procuran que su producto o servicio incluya algo nuevo que sea visto como una ventaja sobre su competencia, se adaptan a la demanda de la gente. Esto nos lleva al concepto de soberanía del consumidor. Es bien sabido en el mundo de la publicidad y las ventas el dicho de que «el cliente siempre lleva la razón», y en efecto, tal y como indica Mises en La Acción Humana:

En la sociedad de mercado corresponde a los empresarios la dirección de los asuntos económicos. Ordenan la producción. Son los pilotos que dirigen el navío. A simple vista, podría parecernos que son ellos los supremos árbitros. Pero no es así. Están sometidos incondicionalmente a las órdenes del capitán, el consumidor. Ni los empresarios, ni los terratenientes, ni los capitalistas deciden qué bienes deban ser producidos. Eso corresponde exclusivamente a los consumidores ${ }^{20}$ (Mises 1980), pp. 328.

${ }^{19}$ Kotler y Amstrong, Fundamentos del Marketing, Pearson Education, Naucalpan de Juárez, Estado de México 2008. P. 5.

${ }^{20}$ Ludwig Von Mises, La Acción Humana, Unión Editorial, Madrid 1980. P. 328. 
En efecto, todos los productos y servicios que aparecen en el mercado van destinados a suplir la demanda constante que existe en el mismo. E incluso cuando una empresa realiza un estudio de mercado para averiguar qué nuevos productos pueden interesar a sus clientes, éste estudio se basa en las preferencias y gustos de dichos consumidores.

Puede sin duda argumentarse que hay ciertos tipos de productos o servicios que son totalmente novedosos y pillan por sorpresa al consumidor, por lo que puede que los creadores de dichos productos no pensasen en ningún caso en suplir las demandas del mismo. Sin embargo incluso los productos o servicios más nuevos y radicalmente innovadores buscan cumplir con unos gustos y deseos que ya venían siendo demandados con anterioridad.

En este sentido es importante remarcar la labor de la empresa Apple. Cuando Steve Jobs (1955-2011) pensaba en cómo el ordenador personal podría ser altamente demandado y rentable para su compañía lo hacía basándose en el hecho de que probablemente el consumidor prefiriese una mayor comunidad al poder trabajar con un ordenador portátil en vez de tener que desplazarse al lugar en el que se encontrasen los grandes ordenadores.

4. Existe en la sociedad occidental cierto odio hacia el mercado y el consumismo, personas que se consideran a sí mismas, cultas, refinadas e intelectuales desprecian sin contemplaciones la propaganda comercial, la sociedad de consumo e incluso el mercado.

Ya desde la antigüedad puede observarse cómo importantes pensadores griegos como Aristóteles despreciaban el comercio al considerar que eran labores mundanas y propias de gente de clase inferior o menor capacidad intelectual. Es notable el odio que profesan por el comercio muchas personas que se consideran intelectualmente superiores a la media, despreciando arrogantemente la labor del comercio e incluso en ciertos casos, reclamando abiertamente y sin tapujos que dicho comercio se regule en base a sus gustos y criterios personales o bien desaparezca.

Tal y como indica el economista Murray Newton Rothbard:

Aristóteles denuncia sin más los intercambios por la ganancia monetaria como inmorales y no naturales, y en particular aquel- 
las actividades como el comercio al por menor, el tráfico y el transporte comerciales, y el alquiler de mano de obra. Especial inquina sentía por el comerciante minorista, directamente al servicio del consumidor, que deseaba desapareciera para siempre ${ }^{21}$ (Rothbard 2013), pp. 44.

Como se ha indicado, este odio, si bien ya puede verse en etapas más tempranas de la historia humana, no se queda ahí. Durante toda la historia han existido procesos de odio hacia el comercio.

El autor Bertrand de Jouvenel (1903-1987), señala en un texto llamado «Los intelectuales europeos y el capitalismo ${ }^{22}$ » cómo han existido ciertos intelectuales que han manifestado su odio hacia el comercio al considerar el mismo como algo mundano, pretendiendo indicar a los consumidores qué se debe comprar y qué no se debe comprar.

El hombre de negocios ofrece al público «bienes», definidos como «todo lo que el público desea comprar»; el intelectual trata de enseñar que está «bien», y para él algunos de los bienes que se ofrecen son cosas de ningún valor y el público debería ser disuadido de desearlas. El mundo de los negocios es para el intelectual un mundo de valores falsos, de motivos bajos, de recompensas mal dirigidas.

Ignoran que la gente tiene gustos distintos y caen en la arrogancia inmensa de pensar que sus propios gustos personales deben ser impuestos como canon de lo moralmente correcto o deseable a nivel social.

A su vez, caen de nuevo en la curiosa incoherencia de criticar el consumo ajeno y no hacer ninguna observación critica del propio.

Por lo tanto, cuando uno de estos «intelectuales» critica la publicidad, el consumismo o el mercado como propio de las mentes más simples, ignora totalmente que es precisamente ese sistema, dedi-

${ }^{21}$ Murray N Rothbard, Historia del pensamiento económico, vol. I, Unión Editorial, Madrid 2013, p. 44.

${ }^{22}$ Bertrand de Jouvenel, Los intelectuales europeos y el capitalismo. Publicado por Jesús Huerta de Soto, en Lecturas de Economía Política, Volumen II, Unión Editorial, Madrid 1987, p. 123. 
cado a ofrecer todo lo que el público desee comprar el que ha hecho que la humanidad avance hasta límites nunca vistos antes en la historia de la especie humana. Caen en el error de creer que las condiciones de vida de las que disfrutan han existido siempre, ignorando que sin el mercado y el consumismo que hipócritamente desdeñan, no podría haber avanzado la humanidad.

Es la economía de mercado libre capitalista la que desde la revolución industrial ha aumentado enormemente la calidad de vida de la sociedad, reduciendo la pobreza a mínimos históricos y aumentando la esperanza de vida.

Tal y como indica Mises:

Si la humanidad hubiera permanecido bloqueada en la condición de una falta de libertad de parte o incluso de la totalidad de los trabajadores, no habría sido posible el magnífico desarrollo de las fuerzas económicas que los últimos ciento cincuenta años han producido. (...) Un trabajador europeo de nuestro tiempo vive en condiciones materiales más favorables y confortables que las de un faraón de Egipto, por más que tuviera a su servicio millares de esclavos, (...) Si fuera posible trasladar un nabab de aquellos tiempos a las condiciones en que hoy vive un ciudadano común, no hay duda de que diría que su vida fue realmente mísera frente a la que puede permitirse el más modesto ciudadano de nuestros días. Tal es el fruto del trabajo libre: consigue crear para todos más riqueza de la que jamás creara en el pasado el trabajo no libre $^{23}$ (Mises 2007), pp. 52-53.

Una vez detalladas estas observaciones, es preciso comparar la definición de propaganda comercial de Mises con la de uno de los publicistas más famosos de España; Luis Basat.

En su obra, El libro rojo de la publicidad ${ }^{24}$ Basat define la misma como «el arte de convencer consumidores», considera que la publicidad tiene parte de arte y parte de ciencia:

${ }^{23}$ Ludwig Von Mises, Liberalismo, la tradición clásica, Unión Editorial, Madrid 2007, p. 52-53.

${ }^{24}$ Luis Bassat, El libro rojo de la publicidad, Plaza \& Janés Editores, S.A. Barcelona 2001. 
Vender es un arte, un arte de hombres y no de genios. Porque tiene en la técnica a su mejor aliado, pero agradece como nadie esa chispa mágica que solo le puede dar la intuición ${ }^{25}$ (Bassat, 2001), pp. 34.

A la hora de tratar cómo se comporta el consumidor indica:

La publicidad es el puente entre el producto, o el servicio, y el consumidor. $Y$ tiene infinitas versiones. Puede ser un puente de piedra o de hierro, romántico o de diseño ultramoderno, seguro o arriesgado, ancho o estrecho, y así sucesivamente ${ }^{26}$ (Bassat, 2001), pp. 36.

Aquí podemos observar como Bassat, sin necesidad de explicar los conceptos de la acción humana, da a entender que la publicidad no es sino un medio para lograr un fin, vender. Al fin y al cabo, la publicidad es la punta de lanza del mercado, y su objetivo es claro; lograr obtener la venta y a ser posible fidelizar al consumidor.

También es remarcable el hecho de que Bassat indica que «el consumidor selecciona la publicidad», cosa obvia. Al fin y al cabo tal y como indica Mises, las valoraciones son subjetivas y cada persona elige el tipo de producto que quiere consumir siendo por tanto afectada por un tipo de anuncio $\mathrm{u}$ otro. A este respecto también menciona de forma indirecta el proceso de competencia constante al que se ven sometidas las marcas, proceso que influye no solo en dichas marcas sino en los propios clientes:

En Estados Unidos se estima que el promedio de exposiciones publicitarias a las que se enfrenta el consumidor puede llegar a las 2.000 diarias (...) No es sorprendente, pues, que el consumidor busque a veces la manera de evitarla. (...) El consumidor es hoy un experto en el uso de técnicas de selección para filtrar los impactos que recibe (...) Sólo hay dos grandes factores en juego en esa selección, sus necesidades, gustos e inquietudes del momento y nuestra capacidad creativa para ser relevantes y llamarles la atención ${ }^{27}$ (Bassat, 2001), pp. 36-37.

\footnotetext{
${ }^{25}$ Op. cit, pp. 34.

${ }^{26}$ Op. cit, pp. 36.

${ }^{27}$ Op. cit, pp. 36-37.
} 
Vemos cómo estas observaciones realizadas por Bassat son totalmente compatibles con la Escuela Austriaca de Economía y su visión subjetiva del valor. Además, es notable el hecho de que Bassat se refiera a la competencia que se genera en el mercado no desde el punto de vista inmediato de las empresas, sino desde los efectos que genera la publicidad en los consumidores.

Si bien Mises es mucho más escueto en su análisis, puesto que no estaba escribiendo un libro de publicidad sino de economía, las conclusiones a las que llegó son bastante similares a las que indica Bassat. Mises se centra en la publicidad como parte del proceso de mercado, llegando a conclusiones lógicas a las que llega de manera a-prioristico-deductivas partiendo del axioma de la acción humana.

Bassat en cambio no pretende hacer un estudio científico sobre el tema, sino un libro de divulgación para que cualquier persona pueda leerlo y entenderlo. Por ello, su enfoque es mucho más sencillo, no entrando a profundizar de forma analítica en los mecanismos económicos que hacen funcionar toda la maquinaria del proceso publicitario, sino que los comenta desde un lenguaje mucho más común y sencillo.

Estos dos mecanismos económicos que generan todo el proceso publicitario tal y como lo conocemos hoy en día son la creatividad y la competencia. Toda la definición técnica de la propaganda comercial de Mises y todo el desarrollo sencillo y creativo del libro de Bassat tratan sobre estos dos conceptos.

Como estudiosos de la economía y basándonos en el método de la Escuela Austriaca sabemos que la chispa que mueve todo este engranaje de creatividad y competencia es la acción humana. Es decir, el hombre al actuar buscando sus propios fines en un mercado libre en el cual tiene muchos competidores, debe por necesidad ser creativo para poder competir y lograr atraer a los máximos consumidores posibles.

Si bien Bassat dedica varios libros a estos dos aspectos, sobre todo al de la creatividad; Mises menciona la propaganda comercial en un capitulo relativamente corto de su obra, que si bien da para sacar amplísimas conclusiones de su visión de la economía, no es suficiente como para que el análisis de la publicidad desde la perspectiva de la Escuela Austriaca se quede ahí. 
Esto se debe a que estos dos conceptos esenciales que forman la publicidad; Creatividad y competencia, han sido profundamente estudiados por varios autores de la escuela. Y si bien Mises logra simplificar el concepto de publicidad y llegar a conclusiones certeras y similares a las de los grandes expertos de la publicidad como Luis Bassat, hay muchos más aportes por parte de autores de la Escuela Austriaca para profundizar en los mismos.

Por ello, en los dos siguientes capítulos vamos a analizar dos teorías propias de la Escuela Austriaca que tratan estos dos aspectos de la publicidad. Las dos han sido desarrolladas por múltiples autores a lo largo de los años. Sin embargo, es el catedrático de economía Jesús Huerta de Soto el que las ha expuesto de manera más clara y concisa, tras estudiar los estudios anteriores y realizar sus propias aportaciones a dichos conceptos.

Tal y cómo hemos dicho, técnicamente, los conceptos de creatividad y competencia; ambos tan importantes en el proceso publicitario, están presentes ambos en la teoría de la Función Empresarial. Sin embargo también merece la pena analizar la Teoría de la Eficiencia Dinámica para analizar las consecuencias que genera constantemente dicha empresarialidad en el mercado.

\section{Creatividad publicitaria y Función Empresarial}

La Teoría de la Función empresarial ha sido desarrollada gracias a la intervención de varios importantes autores como el profesor emérito de la Universidad de Nueva York Israel M. Kirzner, quien desarrollase los conceptos básicos de la misma en su trílogia «Competition and Entrepeneurship ${ }^{28}$ », «Perception, Opportunity and Profit ${ }^{29}$ » $\mathrm{y}$ «Discovery and the Capitalist Process ${ }^{30} »$.

\footnotetext{
${ }^{28}$ Israel M. Kirzner, Competition and Entrepeneurship, The University of Chicago Press, Chicago 1973.

${ }^{29}$ Israel M. Kirzner, Perception, Opportunity and Profit , The University of Chicago Press, Chicago 1979.

${ }^{30}$ Israel M. Kirzner, Discovery and the Capitalist Process , The University of Chicago Press, Chicago 1985.
} 
Sin embargo, ha sido el profesor Jesús Huerta de Soto quien ha dado forma clara a esta teoría en su libro Socialismo, Cálculo Económico y Función Empresarial ${ }^{31}$.

a) La teoría de la función empresarial según Huerta de Soto

En Socialismo, Cálculo Económico y Función Empresarial Huerta de Soto describe la Función Empresarial como:

En un sentido general o amplio la función empresarial coincide con la acción humana misma. (...) ejerce la función empresarial cualquier persona que actúa para modificar el presente y conseguir sus objetivos en el futuro (...) el sentido de empresa como acción está necesaria e inexorablemente unido a una actitud emprendedora, que consiste en intentar continuamente buscar, descubrir, crear o darse cuenta de los nuevos fines y medios ${ }^{32}$ (Huerta de Soto, 1992), pp. 41-43.

Es decir, primero y partiendo del concepto de acción humana, debemos tener en cuenta que esta es «todo comportamiento o conducta deliberada» y que por tanto, el actor o individuo tiene unos fines, a los que valora subjetivamente dando un valor, y unos medios para lograr esos fines, a los que otorga una utilidad subjetiva en función de si le sirven mejor o peor para lograr los fines propuestos.

Todo actor se planifica un modo de actuar o plan de acción para lograr ese objetivo, a esto debe añadirse que el concepto que tenemos de tiempo es puramente subjetivo. Un año puede ser una eternidad para conseguir el fin de un individuo y apenas un suspiro para otro. "Toda acción humana se desarrolla en el tiempo, pero entendido no en el sentido determinista, newtoniano, físico o analógico, sino en su concepción subjetiva ${ }^{33}$ » Huerta de Soto (1992), pp. 45. El actor se dedica a generar expectativas para el futuro.

\footnotetext{
${ }^{31}$ Jesús Huerta de Soto, Socialismo, Cálculo Económico y Función Empresarial, Unión Editorial, Madrid 1992.

32 Op. cit, pp. 41-43.

${ }^{33}$ Op. cit, pp. 45.
} 
Aquí es cuando surge el problema, el futuro es incierto.

No podemos predecir el futuro, es imposible prever todos los escenarios, el futuro es incierto. Nos encontramos ante una situación de plena incertidumbre ante la vida, una incertidumbre que no podemos erradicar y ante la que debemos adaptarnos para no solo poder sobrevivir sino también, poder progresar y prosperar.

Por ello, el ser humano utiliza dos herramientas para poder guiarse en cierta medida en la vida. La primera son las Instituciones Sociales, y la segunda la Función Empresarial.

En el primer apartado habíamos definido a las Instituciones Sociales como una serie de comportamientos pautados que surgen de forma espontánea. Recordemos que estos comportamientos son imitados por la mayoría de individuos, en base a que facilitan la consecución del mayor número posible de objetivos individuales. Dicha imitación conlleva a su vez un proceso de ensayo-error en el cual preponderan los grupos de individuos que eligen el comportamiento más útil para resolver sus problemas y lograr sus objetivos. De tal forma que dichos comportamientos se convierten al ser imitados en hábitos y costumbres que van modificándose con el tiempo, generándose la tendencia de que perduren los mejores, que aprovechando una gran cantidad de información y conocimiento tácito acumulado durante siglos, permiten el desarrollo.

A esto debemos por último añadir que el motor que genera estas instituciones de forma no deliberada es la función empresarial siendo aplicada por millones de individuos a lo largo del tiempo, individuos que modifican el presente adaptándose a esos comportamientos y sometiéndolos a un proceso de ensayo error constante para alcanzar sus objetivos a futuro.

En segundo lugar, los seres humanos para hacer frente a la incertidumbre, recurren a la función empresarial. La misma función empresarial que genera de forma espontánea todo el proceso social es utilizada cada momento por todos los miles de millones de seres humanos vivos.

Dicha Función Empresarial ${ }^{34}$ se caracteriza principalmente por ser creativa.

${ }^{34}$ Por empresarial no se entiende que solo la realicen los empresarios o directivos de grandes empresas sino que se entiende el concepto de emprendimiento. 
Es la creatividad la que mueve todo el proceso de la función empresarial, los seres humanos no podemos ser autárquicos, debemos por ello cooperar y coordinarnos en sociedad. la existencia de un mercado libre en el cual no predominan las relaciones violentas sino los acuerdos voluntarios hace necesario que cada individuo para lograr sus objetivos deba ofrecer algo al resto, de ahí que la creatividad sea esencial y de ahí que esté ligada directamente a la competencia existente entre todos los individuos que forman parte de la sociedad.

Por ello, es necesario explicar brevemente las características de la Función Empresarial que desarrolla el doctor Huerta de Soto.

La primera de todas es la "perspicacia», el actor debe darse cuenta de las oportunidades de ganancia que surgen en su entorno y actuar en consecuencia para aprovecharse de las mismas.

Ello significa crear en nuestra mente una idea que antes no existía, para ello es necesario estar constantemente alerta para así poder darnos cuenta de lo que ocurre a nuestro alrededor y descubrir los deseos que querrán los consumidores en el futuro.

A su vez debemos tener en cuenta que el conocimiento que se genera con la Función empresarial es de tipo creativo. El conocimiento científico puede ayudar a potenciar nuestra capacidad creativa, pero no es tan importante como el «conocimiento empresarial». No adquirir ese conocimiento científico no implica incapacidad para crear conocimiento empresarial, aunque evidentemente el conocimiento científico sea un trampolín de ayuda. La ciencia económica es por tanto un conocimiento científico que estudia los procesos de creación y transmisión del conocimiento práctico (creativo). Estudia en términos abstractos cómo funciona el conocimiento práctico pero no por ello lo conoce. El conocimiento práctico no es algo que pueda saberse con antelación pues son los seres humanos los que lo llevan a cabo.

Además, ese conocimiento es «privativo». Cada ser humano busca unos fines particulares dentro de unas circunstancias históricas irrepetibles. Esto hace que en su mente se genere una información distinta a la de cualquier otra persona, cada persona tiene su propia constelación de detalles.

Pues procede del verbo latino in prehendo-endi-ensum, que significa descubrir, ver, darse cuenta de y atrapar. 
Es también un «conocimiento disperso» en la mente de aquellos seres humanos que lo han generado al actuar, muy pocas veces tenemos todo el conocimiento necesario para llevar a cabo la acción (en los casos en los que poseemos toda la información necesaria la acción es muy simple). Es un Know-How, es decir, un conocimiento que se aprende con el desarrollo de la acción, implica un proceso de practica (ensayo-error), no es un conocimiento que se pueda articular. Es decir, que es también de tipo «tácito no articulable».

Tal y como indica Huerta de Soto:

La función empresarial no supone coste alguno, es esencialmente creativa. (...) Da lugar a unos beneficios que surgen de la nada y que denominaremos Beneficios empresariales puros. Para obtener beneficios empresariales no es preciso por tanto, disponer de medio previo alguno, sino tan sólo es necesario ejercer bien la función empresarial ${ }^{35}$ (Huerta de Soto 1992), pp. 61.

Se produce por tanto un proceso de creación de información de la nada que a su vez es transmitida por el actor al resto de individuos, que se adaptan a la misma en un proceso de coordinación y ajuste que implica aprendizaje en un proceso de competencia continúo.

Como es lógico, la información relevante es siempre subjetiva y no existe al margen de las personas que sean capaces de interpretarla o descubrirla, de forma que son seres humanos los que crean, perciben y transmiten la información (...) la transmisión de información social es básicamente tácita y subjetiva, es decir, no expresada y articulada, y a la vez muy resumida (...) los agentes $(\ldots)$ han aprendido a actuar uno en función del otro (...) aprenden a actuar de forma coordinada (...) Y además aprenden de la mejor forma posible: sin darse cuenta de que están aprendiendo y motu proprio, es decir, voluntariamente y en el contexto de un plan en el que cada uno sigue sus fines e intereses particulares. Este y no otro, es el núcleo del proceso (...) que hace posible la vida en sociedad ${ }^{36}$ (Huerta de Soto, 1992), pp. 65-66.

\footnotetext{
35 Op. cit, pp. 61.

${ }^{36}$ Op. cit, pp. 65-66.
} 
Podemos ver como efectivamente, y en base a la teoría austriaca, las interacciones humanas que generan la sociedad se llevan a cabo en un proceso que genera una cooperación y coordinación espontánea que sufre un proceso de ensayo error constante y se hace posible gracias a la creatividad de la función empresarial (presente en todos los seres humanos) y al uso de las instituciones, y que, a su vez genera una cantidad de información inmensa y constante a la cual los individuos que forman la sociedad van adaptándose.

\section{b) La creatividad publicitaria}

Si por algo se caracteriza la publicidad es por su creatividad. Hacer publicidad no implica un trabajo rutinario ni mucho menos, al contrario, cada cliente, cada campaña y cada situación es un mundo único lleno de matices. A ello hay que sumarle la evolución constante de la sociedad, que hace que los publicistas deban adaptarse sobre la marcha a las nuevas tendencias y tecnologías para así poder expresarse mucho mejor y llegar de forma más directa y personal al público objetivo.

A este respecto, cabe mencionar no solo la obra de Luis Bassat sino también la del premiado creativo publicitario Carlos Navarro Gutiérrez.

En su obra, Creatividad Publicitaria Eficaz ${ }^{37}$, Navarro define la creatividad como:

Un valor añadido a la comunicación publicitaria que despierta determinados sentimientos en el grupo objetivo al que va dirigida, creando un vínculo emocional entre marca y mensaje más fuerte que el meramente informativo. La creatividad es más que pura información. La creatividad es un lazo emotivo entre la marca que lo emite y el receptor ${ }^{38}$ (Navarro, 2010) pp. 36.

${ }^{37}$ Carlos Navarro, Creatividad Publicitaria Eficaz, ESIC Editorial, Madrid 2010 (tercera edición).

38 Op. cit, pp. 36. 
Es interesante el hecho de que lo primero que se diga es que es un valor añadido a la comunicación. Esto puede enlazarse directamente con la función empresarial y la aportación de esta a la institución del lenguaje, también es bastante interesante el hecho de que Navarro indique claramente que «Nadie es creativo en todo. Pero siempre todos podemos ser creativos en algo ${ }^{39}$ » Navarro (2010), pp. 38, pues este mensaje está también directamente relacionado con la Función Empresarial, que afirma que todo ser humano tiene capacidad creativa.

Navarro explica en su libro el proceso o método del creativo publicitario. Lo primero es el Briefing, que no es sino un documento elaborado por el anunciante para indicarle al publicista los datos esenciales que debe tener en cuenta a la hora de anunciar la marca, estos datos suelen ser sobre el segmento de marca, ventajas del producto, competencia y consumidor objetivo.

En sentido estricto, entonces, el briefing dado por el cliente sería el acto de contrastar la información en bruto sobre las características de la marca con las preguntas de un especialista en comunicación que es contratado para convertir las más adecuadas en elementos persuasivos para determinado mercado ${ }^{40}$ (Navarro, 2010), pp. 68.

El briefing es muy importante pues gracias a él, la agencia de publicidad sabrá cuales son las ventajas que tiene el producto de su cliente con respecto a la competencia.

Una vez que en la agencia de publicidad ya saben perfectamente cuales son las ventajas competitivas que diferencian al producto de la competencia haciendo que la marca sea única comienza el trabajo de los creativos publicitarios.

Los creativos publicitarios deben ser individuos muy empáticos que tengan la capacidad empática de ponerse en el lugar del consumidor y saber cómo transmitir al mismo el mensaje, recurriendo para ello a la persuasión. Deben ser personas emocionalmente inteligentes y curiosas.

\footnotetext{
${ }^{39}$ Op. cit, pp. 38.

${ }^{40}$ Op. cit, pp. 68.
} 
Hemos indicado que toda persona tiene capacidad creativa, sin embargo esta capacidad no está igual de desarrollada en todas las personas, tal y como se menciona en la obra de Carlos Navarro, el psicólogo Guildford puso de manifiesto que «en una situación determinada, una persona creativa observará que muchos problemas se plantean ante ella, mientras otra no se dará ni cuenta $a^{41}$ » Navarro (2010), pp. 88.

Normalmente el trabajo de los creativos suele realizarse por pareja, una dupla en la cual uno se encarga del arte, es decir, de la imagen, y otra del copy, es decir, de los textos.

Esto es bastante importante porque cada uno de ellos se encarga de darle forma al mensaje para lograr persuadir al cliente de la mejor forma posible, logrando con ello la venta.

El encargado de arte se ocupará de cosas como el Key Visual, es decir, la imagen clave que muestra la ventaja competitiva, la cual debe ser lo más sorprendente, memorable y adaptable posible. Al mismo tiempo, el copy se ocupará del Claim, que es la frase comercial que canaliza toda la emoción hacia el cliente, distinguiendo claramente el producto de la competencia al resaltar sus ventajas y cualidades.

Vemos como todo el proceso publicitario consiste en modificar el lenguaje escrito y visual para transmitir una poderosa idea al cliente, la idea de que el producto anunciado es el mejor de todos.

Si bien considero que a nivel técnico las definiciones de creatividad publicitaria Carlos Navarro son idóneas para realizar este estudio, conviene analizar brevemente el primer párrafo que escribe Luis Bassat sobre la historia de la creatividad en su obra; La Creatividad:

La inteligencia es lo que ha distinguido al ser humano del resto de los seres vivos. Y su creatividad, surgida por el instinto de supervivencia, lo que cambió el rumbo de la historia ${ }^{42}$ (Bassat 2014), pp. 17.

Esta frase se correlaciona perfectamente con toda la teoría evolutiva de las instituciones de la Escuela Austriaca, la cual desarro-

${ }^{41}$ Op. cit, pp. 88.

${ }_{42}$ Luis Bassat, La Creatividad, Penguin Random House Grupo Editorial, Barcelona 2014. P. 17. 
llo de manera profunda y detallada Friedrich A. Hayek. En efecto la inteligencia no es algo que surgiese y se quedase estanco, permitiendo el desarrollo social. Al revés, la capacidad racional humana es fruto de un proceso evolutivo que se ha dado a la par de la evolución física. Si hay una característica que diferencie a los seres humanos del resto de animales es la capacidad creativa.

Es esta capacidad creativa la que permite que los individuos, al buscar la cooperación y coordinación con los demás, puedan aportar un conocimiento nuevo no visto antes que suponga un avance inmenso para la humanidad. No importa el que unos sean más creativos que otros en según qué cosas. Cada ser humano puede suponer un aporte vital al progreso y desarrollo de la especie.

De ahí la famosa frase de Hayek «Podemos ser muchos y vivir muy bien, o ser pocos y vivir en una cueva».

\section{c) Creatividad publicitaria y función empresarial}

Una vez vistas las características de la Función Empresarial y la creatividad publicitaria, conviene preguntarse cómo encajan estos conceptos.

Por ello, definiré la creatividad comercial como un acto propio de la función empresarial, mediante el cual, el actor (en este caso el creativo publicitario) utiliza la institución del lenguaje como medio para transformar las ventajas competitivas del producto o servicio, logrando así el fin de venderlo en el mercado, aplicando a dicha institución del lenguaje la creatividad propia de la función empresarial. Esto provoca que la institución del lenguaje sirva al actor como medio para crear un vínculo emocional entre el consumidor y la marca a la que representa logrando así la venta del producto o servicio ofertado por la misma.

Para ilustrar el proceso publicitario usaré la misma técnica que utiliza el doctor Jesús Huerta de Soto en Socialismo, Calculo Económico y Función Empresarial, los llamados «monigotes».

Supongamos que el monigote o sujeto A es una marca de coches. En términos concretos ofrece coches a cambio de dinero.

El sujeto B es un individuo que desea comprar un coche, es decir, ofrece dinero a cambio de un coche. 
Para dar a conocer su producto, la marca de coches (A) contrata a C, una agencia publicitaria.

La tarea de $\mathrm{C}$ es tener una idea creativa que, aplicada al lenguaje tanto narrativa como visualmente sepa conectar con el consumidor (B) y transmitirle las ventajas competitivas del producto que ofrece A.

Llevar a cabo esta campaña publicitaria por parte de $C$ tendrá varias consecuencias propias de la función Empresarial:

1. Creación de información de la nada:

Se ha generado una idea creativa que es de tipo Ex Novo, esta información creativa se ha creado en la mente del publicista o los publicistas que hayan trabajado para A. dicha información es un conocimiento puramente subjetivo, no científico, que es interpretado de manera subjetiva por cada persona que accede a la misma. Es un conocimiento privativo y disperso, pues cada uno de los tres actores (Oferente, Agencia y consumidor) busca unos objetivos propios, utilizando este conocimiento que se encuentra diseminado entre ellos para cooperarse y coordinarse. A su vez, la idea creativa ha surgido debido a que el publicista o publicistas que han trabajado en ella ya tenían una experiencia previa, surgida de un proceso de ensayo error constante que se ha dado a lo largo de sus años de trabajo. Por ello, podemos calificar este tipo de conocimiento creativo como tácito y difícilmente articulable. Es decir, es un Know How, el publicista a duras penas puede explicar la totalidad de su propio proceso creativo mental interno.

2. Efecto de transmisión

Según Jesús Huerta de Soto: «la transmisión de información social es básicamente tácita y subjetiva, es decir ni expresa y articulada, y a la vez muy resumida (de hecho se transmite y capta subjetivamente el mínimo imprescindible para coordinar el proceso social); lo cual por otro lado, permite aprovechar de la mejor manera posible la limitada capacidad de la mente humana para crear, descubrir y transmitir constantemente nueva información $^{43}{ }^{4}$. (Huerta de Soto 1992), pp. 66.

${ }^{43}$ Jesús Huerta de Soto, Socialismo, Cálculo Económico y Función Empresarial, Unión Editorial, Madrid 1992. P. 66. 
Es el hecho de que se transmita y capte subjetivamente el mínimo imprescindible para coordinar el proceso social lo que interesa en este caso, pues es lo que hace la propaganda comercial. Las ideas mostradas en el anuncio deben ser siempre lo más básico posibles, buscando que el consumidor en apenas 5 segundos tenga clara cuál es la ventaja competitiva del producto que se le ofrece.

3. Efecto de ajuste y coordinación

Al igual que en el modelo de monigotes de Huerta de Soto, los agentes A y B, en este caso oferente y demandante, han aprendido a actuar coordinadamente al ajustar sus comportamientos uno en función del otro.

Ambos, buscando sus propios fines, han llevado a cabo un proceso coordinado de cooperación social, que tiene como resultado la venta. Ganando el oferente el dinero que demandaba y el demandante el coche que demandaba.

4. Efecto competitivo

Una vez que se han solucionado los desajustes sociales existentes gracias a la función empresarial, estas oportunidades de ganancia desaparecen, por lo que ya no puede ser aprovechada por otra persona del mismo modo, lo que obliga a una competencia constante.

5. Efecto continúo

Todo este proceso empresarial jamás se detiene, pues cada vez que se soluciona un desajuste surgen en cascada nuevos desajustes a solucionar ${ }^{44}$.

Por tanto, como podemos ver, la función empresarial como teoría puede aplicarse perfectamente al proceso creativo publicitario para explicar el proceso de realización de la propaganda que motiva la compra por parte del consumidor, y aun de no comprar el mismo dicho producto, la información producida le sirve para comparar con otras ofertas que encuentre.

${ }^{44}$ Este concepto será explicado con más detalle en el siguiente apartado. 


\section{La teoría de la eficiencia dinámica aplicada a la publicidad}

La Teoría de la Eficiencia Dinámica no es sino un análisis de las consecuencias que tiene la función empresarial en un orden espontáneo dinámico y evolutivo como es el mercado.

Habíamos concluido que junto a la creatividad, la competencia es otro de los factores claves publicitarios, y como podemos observar, todo el proceso creativo mostrado en el apartado anterior, va ligado inseparablemente a un proceso competitivo constante, que es lo que precisamente motiva a los sujetos a tener que usar su creatividad.

Ya en la teoría de la función empresarial el doctor Jesús Huerta de Soto indica que la competencia es una de las características esenciales de la misma, puesto que una vez que el actor descubre una oportunidad de ganancia y actúa en consecuencia para lograrla, esta desaparece. Este proceso de competencia y ajuste y coordinación constante jamás se detiene. En el mercado libre surgen constantemente nuevos productos y servicios que suponen una ventaja inmensa a la hora de facilitar y mejorar la calidad de vida de los consumidores. A este respecto también se refiere Mises en la Acción Humana cuando en su definición de publicidad indica:

El consumidor no es omnisciente. A menudo no sabe dónde encontrar lo que busca al precio más barato posible. Muchas veces incluso ignora qué mercancía o servicio es el más idóneo para suprimir el especifico malestar que le atormenta. El consumidor solo conoce las circunstancias que el mercado registró en el inmediato pretérito. De ahí que la misión de la propaganda comercial consista en brindarle información acerca del actual estado de las cosas $^{45}$ (Mises 1980), pp. 386.

Poco más puede decirse de unas palabras tan sumamente acertadas. Los nuevos productos y servicios que surgen constantemente en el mercado libre debido al proceso competitivo (englobado dentro del motor principal del mercado que es la Función Empresarial) no tienen que ser conocidos por los consumidores. De he-

${ }^{45}$ Ludwig Von Mises, La Acción Humana, Unión Editorial, Madrid 1980. P. 386. 
cho, recordemos como Bassat ya indica que la mayoría de consumidores simplemente ignora la publicidad que ve, de ahí que la creatividad sea tan importante para dicho proceso competitivo dinámico, y viceversa.

El hecho de que estos dos conceptos estén tan entrelazados también se hace patente en la teoría que analizaremos en este punto: La Teoría de la Eficiencia Dinámica ${ }^{46}$.

Huerta de Soto define la eficiencia dinámica al decir:

En un sentido dinámico, puede afirmarse que, por ejemplo, un ser humano, una empresa, una institución o todo un sistema económico, serán tanto más eficientes conforme más y mejor impulsen la creatividad y la coordinación empresarial (...) lo verdaderamente importante no es tanto evitar el despilfarro de unos medios que se consideran conocidos y dados (...) como el descubrir y crear continuamente nuevos fines y medios, impulsando la coordinación y asumiendo que en todo proceso empresarial siempre surgirán nuevos desajustes, por lo que un cierto despilfarro es inevitable y consustancial a toda economía de mercado. (...) puede considerarse que la dimensión dinámica de la eficiencia es la más relevante, pues, de hecho, aunque un sistema económico se encuentre en la frontera de posibilidades de producción, es posible que todos sus agentes salgan ganando si es que la creatividad empresarial mueve constantemente la curva hacia afuera aumentando, así, las posibilidades de todos, gracias a un flujo continuo de creatividad de nuevos fines y medios que, hasta su descubrimiento empresarial, previamente ni siquiera habían podido ser concebidos por nadie ${ }^{47}$ (Huerta de Soto 2014), pp. 23.

Es decir, no solo es la competencia; si bien esta influye debido a que forma parte indisoluble de la Función Empresarial. Es la propia naturaleza de la Acción humana la que, al generar constantemente fines y medios mueva la economía hacia una eficiencia continua.

Tanto Ludwig von Mises como Luis Bassat indican y mencionan la creatividad y la competencia (ya sea de forma indirecta

${ }^{46}$ Jesús Huerta de Soto, Ensayos de Economía Política, Unión Editorial, Madrid 2014.

${ }^{47}$ Op. cit, pp. 23. 
como hace Mises, o de forma directa como hace Bassat) como claves para el desarrollo de la economía. Sin embargo, si bien esto es verdad, está incompleto. Puesto que cualquiera podría pensar que al solucionarse todos los desajustes habidos en la sociedad, se llega a una situación de equilibrio. Y sin embargo, tal y como mostrábamos en el apartado anterior al mencionar el «efecto continuo», cada vez que se resuelve un desajuste se genera de la nada nueva información creativa que modifica el mercado, creando nuevos desajustes en cascada que deben ser solucionados.

Esto es lo que Huerta De Soto denomina como Big Bang Social, «un proceso que jamás se detiene de expansión sin límite del conocimiento y los recursos, apoyado sobre un volumen de información creciente, y que tiende a ser tan coordinado como sea humanamente posible en cada circunstancia histórica ${ }^{48}{ }^{\text {» Huerta de Soto }}$ (2014), pp. 33

Por tanto, podemos sin duda afirmar no solo que las dos características esenciales de la publicidad (creatividad y competencia) estén insertas en la función empresarial, sino que esta a su vez, se encuentra en un proceso evolutivo (de ahí que sea dinámico) constante, y que por tanto, como cualquier institución se somete a un proceso de ensayo error continuo.

Por ello, ahora entendemos como al aumentar el número de oferentes y por ende la competencia entre los mismos, los consumidores aprendieron a pasar de la publicidad, y como a este hecho se adaptaron evolutivamente dichos oferentes, sobreviviendo solo los más aptos a los cambios bruscos del mercado.

Por ello, puede entenderse que Luis Bassat indique que el consumidor busca «información entretenimiento y confianza».

El mero uso de la información probablemente valdría durante un periodo muy limitado de tiempo, hasta que los distintos publicistas solucionaron los desajustes (diferencia de valoraciones subjetivas entre A y B) y surgieron mayores oportunidades a ser resueltas. A su vez aumentaba la cantidad de oferentes por lo que ya no solo bastaba con la información, la publicidad debía llamar la atención. Una vez adaptados los consumidores (B) a esta nueva

${ }^{48}$ Op. cit, pp. 33. 
situación, ya no bastaba con solo entretener, ahora hay que fidelizar y ofrecer confianza.

Es decir, el proceso evolutivo constante del mercado hace que el consumidor se adapte a los mensajes publicitarios y los ignore, de tal forma que el creativo publicitario tenga que estar recurriendo constantemente a nuevas técnicas que llamen su atención. De ahí que pueda entenderse que una vez que los consumidores se han adaptado a una información concreta, entretenimiento y una fidelización, surjan nuevas técnicas como el Marketing (destinado a fidelizar a esos consumidores y atraer a nuevos) y la Responsabilidad Social Corporativa (que ya no solo intenta vender el producto sino también la imagen de la empresa para posicionarse entre cientos de competidores como una empresa digna)

Por tanto, la pregunta que nos queda es ¿puede considerarse la publicidad cómo una institución evolutiva propia?

\section{4. ¿Puede considerarse la publicidad cómo una institución evolutiva propia?}

En este apartado, pretendo sacar unas pequeñas conclusiones de los tres apartados anteriores, dichas conclusiones luego serán matizadas en el apartado propio que se dedique a las conclusiones de estos cuatro primeros apartados y de los dos siguientes.

Recapitulemos pues, los elementos más importantes de los apartados anteriores:

1. Las características más importantes de la publicidad son la creatividad y la competencia, ambas pueden encontrase mencionadas tanto de forma directa como indirecta por autores de la Escuela Austriaca de Economía y destacados publicistas. Además la visión de la escuela sobre la publicidad o propaganda comercial coincide plenamente con las definiciones de publicidad de destacados expertos en la materia.

2. Estas dos características pueden incluirse en la Función empresarial, la cual, a su vez genera un proceso de eficiencia dinámico constante que se puede considerar de tipo evolutivo. 
Por tanto, ¿puede considerarse la publicidad cómo una institución propia?

Personalmente creo que no, creo que la publicidad y su evolución en complejidad y eficiencia es resultado de que la sociedad sea un orden espontáneo gigante en crecimiento.

Habíamos definido a las instituciones como órdenes espontáneos evolutivos, o comportamientos pautados que sufren un proceso constante de ensayo error que se extiende en periodos muy dilatados de tiempo que superan nuestra capacidad de asimilación. Estas instituciones serían el mercado, el dinero, el derecho, la moral, el lenguaje o la familia.

A mi juicio no se trata de que la publicidad sea una institución propia y separada de las anteriormente mencionadas, sino que es precisamente resultado de la interacción de tres de ellas.

Estas tres instituciones son: El mercado, el lenguaje y la moral.

Evidentemente, sería absurdo considerar que la publicidad pudiese no tener nada que ver con el lenguaje o el mercado, puesto que básicamente es una herramienta creativa que lo que hace es utilizar el lenguaje para vender en el mercado.

Para una mejor comprensión, supongamos que el mercado y el lenguaje son dos esferas bien delimitadas, la publicidad ocuparía la intersección entre ambas:



$\mathrm{Al}$ igual que el mercado y el lenguaje evolucionan en un proceso constante de ensayo error, que, ceteris paribus tiende a la efi- 
ciencia, también lo hace la intersección que hay entre ambas, es decir; la publicidad.

Es decir, que si bien al principio solo era necesaria la mera información para vender un producto, conforme la cantidad de información y el número de oferentes fue aumentando, los consumidores aprendieron a ignorar la publicidad, teniendo los publicistas que hacer frente a este hecho, ofreciendo entretenimiento y utilizando la creatividad para lograr mensajes sorprendentes que captasen su atención rápidamente. Cuando posteriormente esto no ha sido suficiente han ofrecido confianza, para así lograr la fidelización y no solo atraer nuevos clientes sino evitar que los que ya están se vayan a la competencia.

A este proceso evolutivo se ha unido una tercera institución, la moral.

Atraer a nuevos clientes y evitar que estos se vayan a la competencia (lo que hace el marketing), implica que tienes que mantenerlos vendiendo la imagen de la empresa lo mejor posible. Esto se ha sumado a un aumento inmenso del mercado, es decir, el mercado actual, aunque no sea $100 \%$ libre y este muy intervenido en múltiples sectores, está sufriendo un proceso de expansión inmenso, propiciado además por las nuevas tecnologías (que por suerte, cada vez son más difíciles de controlar por parte del gobierno) y esto ha provocado que la oferta de productos y servicios en el mercado sea la más grande vista nunca hasta la fecha.

Por lo que, si sumamos el deseo de las empresas de vender mejor su imagen y con el hecho de que hay más productos y servicios disponibles que nunca antes, es normal entender que los clientes exijan que esos planteamientos éticos que ofrecen las empresas sean verdaderos si quieren mantenerles como clientes.

Ya no es el cliente el que se preocupa por buscar a la empresa, ahora es la empresa la que se preocupa por mantener a los clientes.

El mercado es la soberanía del consumidor, y el avance evolutivo y constante del mismo ha propiciado que, una persona que busque sus propios beneficios a cambio de ofrecer algo al resto, no solo tenga que ofrecer, lo mejor, lo más barato y lo que mejor calidad tiene. Sino que también ahora, tiene que ofrecer lo más ético y moral. 
Esta es la magia del mercado libre, millones de personas buscando sus propios objetivos individuales a cambio de ofrecer exponencialmente al resto, lo mejor de lo mejor.

Este nuevo planteamiento ético es el que a mi juicio representa la responsabilidad social corporativa.

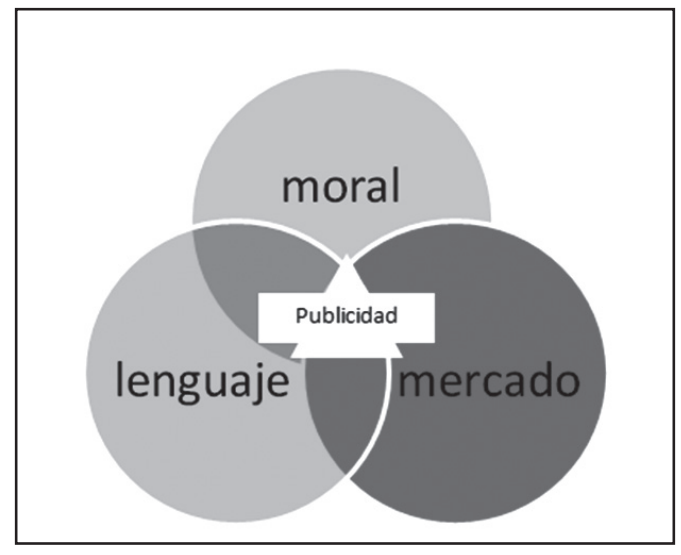

Con esto se explica de alguna forma que la sociedad sea un orden espontáneo gigante, u orden sin plan, como lo llamaba Hayek, no es que sea un único orden, sino que son todas las instituciones u órdenes a la vez. Cuanto mayor sea el grado de evolución de las mismas, mejor será (ceteris paribus) el grado de coordinación entre las todas ellas.

III

\section{LA PUBLICIDAD Y LA COERCIÓN INSTITUCIONAL}

\section{La publicidad ¿condiciona o engaña?}

Es habitual entre la gente, encontrar la opinión de que la publicidad engaña. Cuando esta acusación se cae por su propio peso, suele la gente recurrir a decir que la publicidad si bien no engaña, nos condiciona completamente como si de un imán del que no pudiésemos escapar se tratase. Muchos de los que tales cosas afirman, 
defienden además que la publicidad sea controlada gubernamentalmente.

Sobre si la publicidad engaña; si bien pueden darse ciertos casos de anunciantes que usen el engaño, esto a largo plazo no tiene ningún sentido, siendo una estrategia suicida.

Una de las características principales de la publicidad o propaganda comercia es que puede experimentarse por el consumidor. Es decir, todo anuncio resalta las ventajas competitivas del producto que publicita, los consumidores al comprar dicho producto van a poder comprobar si las ventajas competitivas del mismo se corresponden con las anunciadas.

No tendría sentido, por tanto, que una empresa se dedicase a engañar al consumidor, y menos cuando la competencia es tan elevada.

Para ganar dinero la empresa debe no solo atraer nuevos consumidores mejorando e innovando constantemente en productos y servicios, sino también, mantener a los que ya tiene y dar una imagen ética a todo el mundo, inclusive aquellas personas que no son sus clientes potenciales.

Luego, sería absurdo que un empresario se dedicase a engañar a sus clientes, pues estos se darían cuenta tarde o temprano, marchándose a la competencia, la cual además podría usar eso en su contra $y$, con el añadido de que probablemente dicho engaño sería conocido entre mucha gente, quedando la imagen de la empresa arruinada y con imposibilidad por tanto de atraer nuevos públicos.

Cuanto más sea la empresa mayor será el daño a su imagen por el resultado de una mentira que inevitablemente va a ser descubierta. Luego la afirmación de muchos de que las grandes empresas del mercado se dedican a mentir a sus consumidores constantemente por lógica no se sostiene.

Pero al igual que la mentira no se sostiene como práctica lógica y propia de un empresario que quiera ganar dinero, tampoco se sostiene la idea de que la publicidad nos condiciona totalmente obligándonos a comprar de todo, lo queramos nosotros o no. A este respecto ya se refirió muy claramente Mises en 1949 al escribir sobre publicidad en La Acción Humana:

Es un error harto extendido suponer que una propaganda hábilmente dirigida es capaz de inducir a los consumidores a comprar 
todo aquello que el anunciante se proponga. Según esto, el consumidor se hallaría completamente indefenso ante una publicidad enérgica. El éxito o el fracaso en el mundo mercantil dependería exclusivamente del elemento publicitario. Sin embargo, nadie se atrevería a afirmar que la publicidad habría podido proteger a los fabricantes de cirios y velas ante la competencia de la bombilla eléctrica, a los coches de caballos ante los automóviles y a la pluma de ganso, primero ante la de acero y después ante la estilográfica o el bolígrafo ${ }^{49}$ (Mises 1980), pp. 387.

En efecto, si los anuncios indujesen al consumidor a comprar todo cuanto viese anunciado la desaparición del mercado de productos poco competitivos simplemente no se habría dado, de tal forma que hoy veríamos coexistir trenes de alta velocidad con ferrocarriles impulsados por vapor.

De hecho, de ser esa suposición cierta, ni siquiera se habría producido evolución alguna en la publicidad. No habría pasado de ser mera información para luego entretener y tener que sorprender posteriormente al consumidor, ni existirían tales cosas como el marketing o la responsabilidad social corporativa. Puesto que solo con la simple información bastaría para que los consumidores comprasen todo lo que quisiesen. Tampoco podría decirse que existen distintos públicos objetivos de ser cierto ese caso, puesto que todo el mundo compraría todo lo que se anunciase sin importar de qué producto se tratase. El mercado simplemente no sería meritocrático.

Sin embargo ni la publicidad condiciona total y radicalmente al consumidor ni a los empresarios les conviene mentir si son sensatos y desean obtener ganancias.

Si precisamente se ha podido dar una evolución en la publicidad y en el mercado es por el hecho de que la condición natural del mercado es que es libre.

La libertad es una condición indispensable para que las instituciones sociales evolutivas puedan tender a funcionar correctamente, generando beneficios en la sociedad derivados del progreso que

${ }^{49}$ Ludwig Von Mises, La Acción Humana, Unión Editorial, Madrid 1980. P. 387. 
provocan las mismas al implementar su utilidad para con los individuos que las usan.

Si los individuos pueden realizar intercambios voluntarios, podrán estos experimentar los procesos de ensayo error constante al que están sometidas las instituciones, de tal forma que la tendencia es que dichos procesos de ensayo error vayan indicando a los individuos que actitudes son beneficiosas y cuáles no.

La libertad es además la que permite que dicha institución evolutiva pueda evolucionar. No solo que pueda tender a funcionar bien generando buenos resultados en la sociedad, sino que pueda evolucionar.

Al fin y al cabo, no hay un único grupo objetivo mundial que compre todo lo que la publicidad anuncie, como se deriva de las afirmaciones de ciertas personas con respecto a la publicidad. Al revés, hay cientos de miles de públicos objetivos, hasta el punto de que cada individuo que compone la sociedad es un público objetivo en sí mismo, con sus características propias y únicas.

Como sabemos, esto es algo que se debe a que cada individuo tiene unas valoraciones subjetivas propias, lo que permite que, al actuar estos en su propio beneficio, ejerciendo la función empresarial, se dé por lógica en el mercado un proceso de competencia, en el cual todos aquellos que quieren ganar algo ofreciendo algo cambio a los demás (característica fundamental de la economía de mercado capitalista) tengan que verse obligados a competir.

Esto es algo que resalta Luis Bassat en su obra, El libro rojo de la publicidad al decir en un apartado titulado La publicidad desarrolla la libertad de elección:

Fernando Romero, consejero delegado de Bassat, Ogilvy \& Mather en Madrid, escribe en su ensayo El derecho a elegir: "el marketing es una viva expresión de la democracia. En las manos del comprador esta la decisión de la elección. Día a día está refrendando con sus actos el camino del éxito y del fracaso de los políticos y los productos. Podríamos decir que con su voto cada cuatro años está comprando. Comprando ideas, esperanzas, proyectos. Y, sobre todo, ejerciendo su derecho a elegir ${ }^{50}$ (Bassat 2001), pp. 53

${ }^{50}$ Luis Bassat, El libro rojo de la publicidad, Plaza \& Janés Editores, S.A. Barcelona 2001. P. 53. 
A mi juicio personal, el mercado, es el único que implica un acto puro y constante de democracia, que además está ligado al que verdaderamente debe ser el soberano, el individuo.

Lo que comúnmente se conoce como democracia; las votaciones políticas, es a mi juicio inmoral y peligroso, puesto que el sistema democrático entendido como la elección de políticos o refrendo de leyes por las urnas implica que la soberanía no la tiene el individuo, sino la sociedad.

De tal forma, que si la mayoría de la sociedad decide someter a la minoría contra su voluntad, ello es visto como algo bueno, normal y aceptable.

Esto no es visto con buenos ojos por mi parte por varios motivos:

1. A prácticamente ningún individuo le gusta que se impongan sobre él, controlando su vida y limitando su libertad, guiándole como si fuese un simple cordero. Por lo que, si la democracia "política» o de elección de políticos se aplica como tal, siempre habrá una minoría no contenta a la que se le obligue a cumplir con lo designado por la mayoría.

2. Esta minoría no podrá escapar en ningún caso de la decisión general que la someta, puesto que la característica principal de la democracia «del estado» es que es de tipo coercitivo, uno no puede no acatar lo votado argumentando que no está de acuerdo con ello.

3. Esto implica básicamente una sociedad de acuerdos hegemónicos de orden y mando, en la cual solo se fomenta el odio entre individuos y el surgimiento de conflictos que impidan que dicha sociedad avance hacia una mayor cooperación y coordinación, dañando así las posibilidades de prosperidad.

En cambio, y a diferencia de la democracia política, la democracia que implica el mercado sí que creo que sea buena, puesto que el beneficiario es el individuo y no la mayoría social, es decir:

1. Es totalmente voluntaria, de tal forma que en ningún caso se dan acuerdos hegemónicos sino contractuales, de tipo voluntario. 
2. Al ser voluntaria, cada individuo puede elegir libremente suscribiéndose al consumo del producto o servicio que más le guste y abandonando dicho consumo cuando así lo estime él oportuno.

3. Esto implica una sociedad de acuerdos voluntarios en la cual pueden desarrollarse las instituciones como el mercado, el derecho, el dinero o la moral en base a un proceso de ensayo error constante en el cual los individuos se adscriben a un producto $\mathrm{u}$ otro en base a sus valoraciones subjetivas personales.

4. Es además acorde con las normas morales básicas dado que al ser una sociedad de acuerdos voluntarios se evitan los conflictos derivados de la hegemonía de los unos contra los otros que vemos hoy en día con el sistema democrático político.

Que el mercado este hoy por hoy muy intervenido no es sino porque el estado limita la libertad de los individuos para realizar intercambios voluntarios mediante la coerción institucional.

Por ello, resulta llamativo que aquellos que en base a buscar una «mejor publicidad» la critiquen falsamente por condicionar totalmente y/o mentir, pidan normalmente que la misma se regule, puesto que para buscar la mejor publicidad posible, que verdaderamente beneficie a los consumidores (verdaderos soberanos de la economía de mercado) no hay sino que dejar la mayor libertad posible evitando toda regulación publicitaria, es decir, todo lo contrario a lo que piden.

\section{2. ¿Es necesario limitar la publicidad?}

Como hemos visto en el apartado anterior, no tiene sentido regular la publicidad porque precisamente para que esta funcione eficazmente y, realice por ello la labor social de informar a los individuos que componen la sociedad sobre qué productos y servicios se ofrecen y cuáles son sus características y ventajas, debe ser totalmente libre y no estar en ningún caso intervenida o regulada, de tal forma que los individuos puedan experimentar si lo anunciado se corresponde con la realidad y obrando en consecuencia.

Quizás el ejemplo más famoso de esto sea la híper regulación que hay por parte del estado sobre el tabaco. 
Los estudios que indican que fumar da altas probabilidades de generar cáncer de pulmón son de sobra conocidos por la sociedad, es bien sabido que fumar daña la salud. ¿Tiene por tanto sentido que el estado limite constantemente la publicidad sobre el tabaco? Evidentemente no, todo el mundo que fuma sabe que ello conlleva un daño a su salud, y, evidentemente se prohíbe la venta a menores de edad que no puedan estar bien informados de ello o no sean lo suficientemente maduros como para sopesar las consecuencias de una decisión así.

Por tanto, si la gente adulta sabe perfectamente a lo que se expone cuando fuma, ¿por qué el estado sigue impidiendo la publicidad tabacalera?

Porque el estado cree tener el deber de cuidar nuestra salud aun a costa de impedirnos tomar a nosotros mismos las decisiones sobre qué queremos hacer con ella. Es decir, incluso si alguien conscientemente quiere fumar, el estado hace todo lo posible para impedírselo, limitando la publicidad tabacalera, obligando a dichas empresas tabacaleras a anunciar que el tabaco puede matar en sus productos y gravando con altísimos impuestos la compra de los mismos.

De hecho, en ciertos casos, la burla que realizan los políticos y el estado a la sociedad es descarada, esto puede verse en la publicidad que el estado obliga a poner a las tabacaleras en sus productos en Italia:

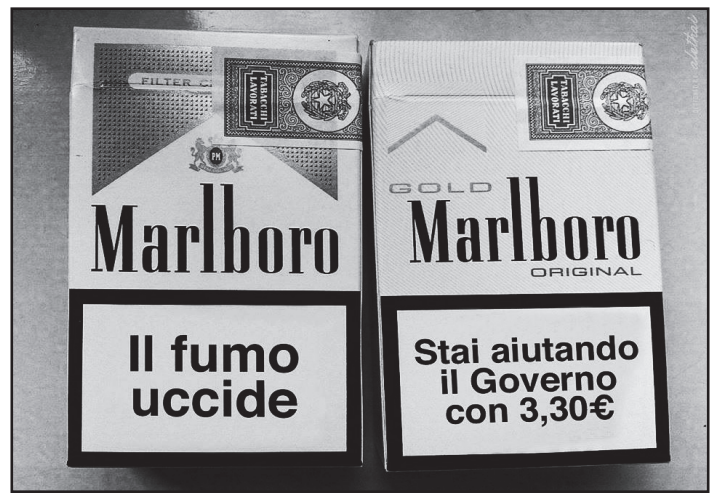

En la imagen puede leerse: en el primer cartel «El tabaco mata», en la modificación posterior: «estás ayudando al gobierno con 3,30€» 
En efecto, el estado sabe que el tabaco es un producto adictivo para aquellos que lo consumen, y no tiene ningún reparo en gravar con altos impuestos dicho producto, ni siquiera ya intenta ocultar sus intenciones diciendo que pretende proteger al fumador de sus propias decisiones libres, simplemente se limita a robarle descaradamente riéndose de él.

En este gráfico de 2013 puede observarse los impuestos que pone el estado al tabaco. Cuyo precio en ese momento era de 4,65€, de los cuales 3,826€ eran impuestos, es decir, el 82,28\% ${ }^{51}$.



Resulta altamente irónico que precisamente sea el estado y sus políticos los que limiten la propaganda comercial cuando precisamente esta es experimentable por la sociedad y por ende supone un proceso de ensayo error positivo para el consumidor, mientras que la propaganda política, no es experimentable ni está regulada aun a pesar de usar mentiras deliberadamente dañando a los votantes.

En efecto, si bien hemos podido ver todas las ventajas de la propaganda comercial o publicidad para con la sociedad, y la necesidad

${ }^{51}$ Gráfico obtenido de http://www.estadolimitado.com/ 
de que esta sea lo más libre posible estando exenta de regulaciones, no pasa así con la propaganda política, a pesar de ser esta altamente nociva para la sociedad.

Los motivos de que esto sea así son varios:

1. Las propuestas políticas no son vinculantes. Es decir, si una empresa te ofrece algo y luego resulta que te ha mentido descaradamente (lanzan un refresco que promete hacerte rejuvenecer 10 años literalmente) el consumidor puede demandar a esa empresa por estafarle. En cambio un político puede prometer cualquier cosa sin preocuparse de cumplirla una vez ha llegado al poder.

2. Usa la mentira. Mientras que a una empresa no le interesa hacer publicidad o propaganda comercial basándose en mentiras (como vimos en el apartado anterior, al político le interesa mentir lo máximo posible para llegar al poder. Esto ha provocado que ciertos políticos hayan elaborado detalladas técnicas a usar para engañar a sus votantes.

En concreto son tristemente famosos los 11 principios de la propaganda política del ministro de propaganda nazi Joseph Goebbels, quien como ministro de educación nazi escribió en 1933 los 11 principios de la propaganda estatal.

Estos principios son usados en mayor o menor medida por todos los partidos políticos, cuanto más populista sea más los usará y viceversa:

1. Principio de la negación y del enemigo único:

Individualizar al adversario en un enemigo único.

2. Principio del método de contagio:

Reunir a varios adversarios en la misma categoría

3. Principio de la transposición:

Consiste en cargar contra el adversario los propios errores o defectos o incluso inventar noticias falsas.

4. Principio de la exageración y la desfiguración:

Convertir cualquier anécdota en amenaza grave.

5. Principio de la vulgarización:

La propaganda política debe ser popular, luego tiene que adaptarse al nivel menos inteligente de aquellos a los que se dirige. 
6. Principio de la orquestación:

Debe haber un número pequeño de ideas repetidas incansablemente.

7. Principio de la renovación:

Hay que emitir argumentos nuevos para que cuando el adversario responda el público este ya en otra cosa.

8. Principio de la verosimilitud:

Construir argumentos de fuentes diversas.

9. Principio de la silenciación:

Disimular las noticias que favorecen al adversario.

10. Principio de la transfusión:

Se opera a partir de un sustrato existente, sea mitología nacional o colectiva.

11. Principio de la unanimidad:

Convencer y aglutinar al mayor número de personas posibles haciendo que muchas otras caigan en la falacia del argumento ad populum

Como podemos ver; mientras que la propaganda comercial o publicidad está destinada a satisfacer en mayor medida las demandas de los consumidores y mejorar la sociedad debido al proceso evolutivo constante de ensayo error al que está sometida la misma, la propaganda política está destinada a mentir a la sociedad deliberadamente para poder así acceder al poder y manipularla desde arriba contra su voluntad.

Por tanto y como conclusión a este segundo apartado, no solo rechazo que se limite y controle la publicidad o propaganda comercial sino que me sumo a la advertencia de muchos sobre la propaganda política y los graves peligros que conlleva para con la cooperación y coordinación en libertad de los individuos que forman la sociedad y los altísimos peligros que supone para el progreso de la misma.

IV

CONCLUSIONES

Como hemos podido comprobar, la relación entre la definición y los argumentos sobre la publicidad del economista austriaco 
Ludwig Von Mises (1871- 1973) y los argumentos de muchos de los mejores y más destacados publicistas del momento es muy estrecha, siendo coherente toda la teoría económica e institucional austriaca con el mundo de la publicidad, el marketing y la responsabilidad social corporativa.

Podemos definir la publicidad como el método de comunicación cuyo fin es convencer al consumidor de que el producto o servicio anunciado es el idóneo para él, y que, para lograr dicho fin utiliza la creatividad como medio.

De tal forma que la creatividad publicitaria es acto propio de la función empresarial, mediante el cual, el actor (en este caso el creativo publicitario) utiliza la institución del lenguaje como medio para transformar las ventajas competitivas del producto o servicio, logrando así el fin de venderlo en el mercado, aplicando a dicha institución del lenguaje la creatividad propia de la función empresarial. Esto provoca que la institución del lenguaje sirva al actor como medio para crear un vínculo emocional entre el consumidor y la marca a la que representa logrando así la venta del producto o servicio ofertado por la misma.

Este método de comunicación que utiliza la creatividad para lograr vender el producto o servicio que publicita es el resultado de la interacción entre la institución del lenguaje y la institución del mercado, de tal forma que a la vez que estas dos evolucionan también lo hace dicho método, adaptándose a las nuevas características del lenguaje y del mercado. Es decir, está sometido a un proceso evolutivo que resulta en un proceso de ensayo error constante.

Por ello, el método publicitario evoluciona a la par de la institución del mercado y el lenguaje. De tal forma que al mismo tiempo que la publicidad resuelve los desajustes dados en el mercado se crea nueva información constantemente a la que se adaptan los consumidores.

Si bien es un método principalmente informativo, una vez que los consumidores se han adaptaron a una información concreta, tuvieron los publicitarios que ofrecer entretenimiento y buscar una mejor calidad en el servicio para lograr la fidelización, pero el mercado sigue evolucionando siendo cada vez mayor la cantidad de oferentes, de ahí que los consumidores ya no quieran el producto más barato y de mejor calidad, sino el ofrecido por la mejor empresa, surgiendo así la Responsabilidad Social Corporativa. 
El método de comunicación publicitario seguirá evolucionando para adaptarse a los nuevos desafíos que presente el resultado de la evolución del mercado y el lenguaje, tendiendo así a satisfacer a los consumidores al comunicarles de la mejor manera posible las ventajas competitivas del producto o servicio que ofrece con respecto a su competencia y la calidad de la empresa que ofrece dicho producto o servicio.

Pero para que esto pueda seguir siendo así, para que sea el consumidor el soberano a cuya demanda se adapten constantemente las decisiones de los oferentes debe haber libertad de mercado. Es decir, no debe estar la publicidad limitada ni coaccionada por parte del estado en ningún caso, para que así ese proceso de evolución constante no se detenga, pudiendo seguir así beneficiando a los consumidores.

A esto hay que añadir una clara advertencia sobre el peligro que presenta la propaganda política, la cual a diferencia de la publicidad comercial se dedica a utilizar el engaño y la mentira para que los políticos puedan controlar la vida de las personas fácilmente y dirigirla de manera coercitiva. Generando así conflictos sociales constantes que dañan la cooperación y la coordinación entre los individuos que forman la sociedad y siendo por tanto un peligro para el progreso humano.

\section{REFERENCIAS BIBLIOGRÁFICAS}

Bertrand de Jouvenel, Los intelectuales Europeos y el capitalismo. Publicado por Jesús Huerta de Soto, en Lecturas de Economía Política, Volumen II, Unión Editorial, Madrid 1987.

Carlos Navarro, Creatividad Publicitaria Eficaz, ESIC Editorial, Madrid 2010 (tercera edición).

Carl Menger, Principios de Economía política, Unión Editorial, Madrid 1983.

César Martínez Meseguer, La teoría evolutiva de las instituciones, la perspectiva austriaca, Unión Editorial, Madrid 2006.

http://www.estadolimitado.com/

IsRael M. KIRZNER, Competition and Entrepeneurship, The University of Chicago Press, Chicago 1973. 
- Discovery and the Capitalist Process, The University of Chicago Press, Chicago 1985.

- Perception, Opportunity and Profit, The University of Chicago Press, Chicago 1979.

Jesús Huerta De Soto, Ensayos de Economía Política, Unión Editorial, Madrid 2014.

- Socialismo, Cálculo Económico y Función Empresarial, Unión Editorial, Madrid 1992.

Kotler y Amstrong, Fundamentos del Marketing, Pearson Education, Naucalpan de Juárez, Estado de México 2008.

Ludwig VON Mises, La Acción Humana, Unión Editorial, Madrid 1980.

- Liberalismo, la tradición clásica, Unión Editorial, Madrid 2007.

LuIs BAssat, El libro rojo de la publicidad, Plaza \& Janés Editores, S.A. Barcelona 2001.

- La Creatividad, Penguin Random House Grupo Editorial, Barcelona 2014.

Murray N Rothbard, Historia del pensamiento económico, vol. I, Unión Editorial. Madrid 2013 